\title{
FRANK BERIBERI IN A 4-MONTH-OLD INFANT
}

BY

\author{
TADEUSZ GIZA and JERZY ARMATA \\ From the Children's Clinic, formerly in the Jagiellonian University of Cracow
}

(RECEIVED FOR PUBLICATION NOVEMBER 5, 1957)

\section{Case History}

A boy, S.A. 4785/344, aged 4 months, was admitted to the Clinic on February 14, 1957. He was the third child of healthy parents and was born without complications after a normal pregnancy, weighing $4 \mathrm{Kg}$. The developmental pattern was normal and he never had any illnesses. He was breast-fed till he was 3 months old and he was then given a butter-flour mixture, prepared from overmilled wheat meal. No juices were regularly added, nor any vitamins supplied.

The illness started suddenly with anorexia. The baby was disinclined to feed from the bottle, milk was regurgitated, but not water. He was restless and whining. Constipation, diminished excretion of urine, hoarseness and stiffness of the neck occurred. Two days before admission the child was pale, dyspnoeic, drowsy and had developed diarrhoea.

Upon admission the patient looked acutely and gravely ill. He was cyanosed, there was extreme tachycardia and respirations were 80 to the minute and grunting in character. Nevertheless he was obviously a welldeveloped and well-nourished child. He weighed $7 \cdot 1 \mathrm{Kg}$. and was $67 \mathrm{~cm}$. long. His temperature was normal.

Physical examination revealed rachitic craniotabes, tense and bulging fontanelle, opisthotonos, distension and pulsation of the cervical veins and bilateral loss of the patellar reflexes. There was definite cardiac enlargement in all diameters, with the apical impulse in the left anterior axillary line. Heart sounds were muffled and distant, of poor quality, and the second pulmonic sound was accentuated. A marked gallop rhythm was present. The liver was palpable two fingerbreadths below the right costal border.

Laboratory findings were as follows: Tuberculin skin tests were negative. Wassermann reaction of the blood and cerebrospinal fluid was negative. The erythrocyte sedimentation rate was normal. Examination of the peripheral blood showed haemoglobin $62 \%$, red blood cell count $4 \cdot 3$ million, white blood cell count 10,680 , with $35 \%$ polymorphonuclears, $3 \%$ band forms, $61 \%$ lymphocytes and $1 \%$ monocytes. The total serum protein was $6.45 \mathrm{~g}$. per $100 \mathrm{ml}$, albumin 5.41 and globulin $1.04 \mathrm{~g}$. per $100 \mathrm{ml}$; serum calcium $9.9 \mathrm{mg}$. \% and phosphate $4.7 \mathrm{mg}$. \%. The cerebrospinal fluid showed a cell count of 4 lymphocytes per c.mm., $20 \mathrm{mg}$. per $100 \mathrm{ml}$. total protein and $70 \mathrm{mg}$. per $100 \mathrm{ml}$. sugar.

Routine urine analysis was normal. However, testing for phenylpyruvic acid by adding a few drops of $10 \%$ ferric chloride solution to the urine acidified with dilute sulphuric acid, produced an intense dark bluish green colour.

A radiograph of the chest showed a generally enlarged cardiac shadow with an enlarged right atrium and with a loss of muscular tone (Fig. 1). The radiographic

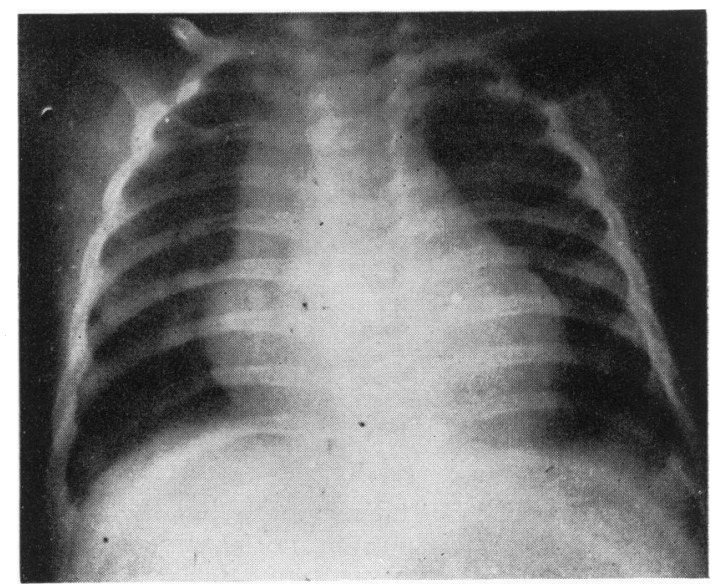

FIG. 1.-Radiograph of chest showing enlarged cardiac shadow with increase of right atrium and loss of muscle tone.

examination of the skull and long bones disclosed evidence typical of rickets.

The electrocardiogram revealed a left ventricular preponderance with shortening of the P-R interval, a prolonged $Q-T$ interval and inversion of $T$ in the praecordial leads (Fig. 2).

As far as the differential diagnosis was concerned, the dominating symptoms were those of acute cardiac insufficiency. Various possible diagnoses were entertained initially. For instance the cardiac type of infantile paralysis the more so as the patellar reflexes were abolished; fibroelastosis; after the onset of neurological signs, rhabdomyoblastosis, which, associated with tuberous sclerosis, gives the so-called Bourneville's disease; and lastly diphtheria, in spite of the lack of any suggestive history or findings.

The definitive recognition came ex iuvantibus. A dramatic change in the apparently hopeless condition 


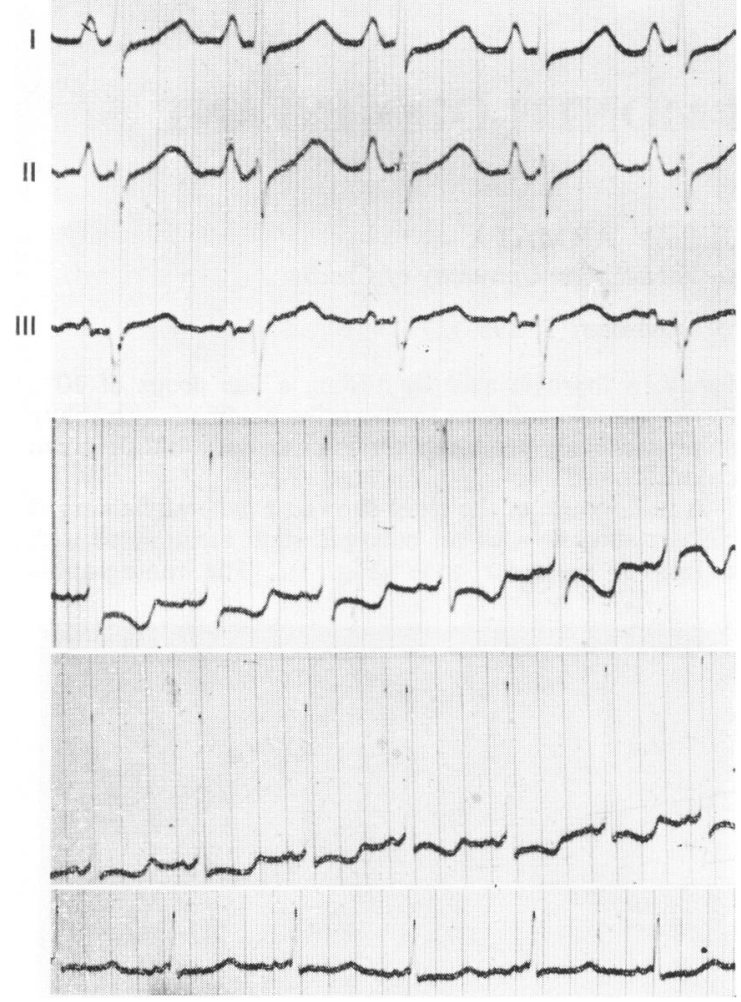

Fig. 2.-Electrocardiogram in case of frank beriberi in infant.

of the patient following the administration of vitamin $\mathbf{B}_{1}$ on the third day after admission anticipated the diagnosis.

Forty-eight hours after the intramuscular administration of thiamine, in a dose of $50 \mathrm{mg}$. daily, the appetite returned rapidly and also the normal skin colouration. The dyspnoea disappeared and respirations dropped to 40 to the minute, the pulse decreased to 120 per minute and there was a progressive decrease in all dimensions of the heart, the sounds of which became louder and clearer. The knee-jerks reappeared on the seventh day. In the second week the heart returned to its normal limits (Fig. 3) and phenylpyruvic acid could no longer be found in the urine. From this time on vitamin $B_{1}$ was continued orally. The boy was discharged 23 days after admittance.

\section{Discussion}

Special mention should be made of the excretion of phenylpyruvic acid in the urine of this patient. He was a full-term baby and did not receive a high protein diet. His mental development did not seem to be affected, his hair was rather dark, the sclerae white and there was no muscular hypertonicity,

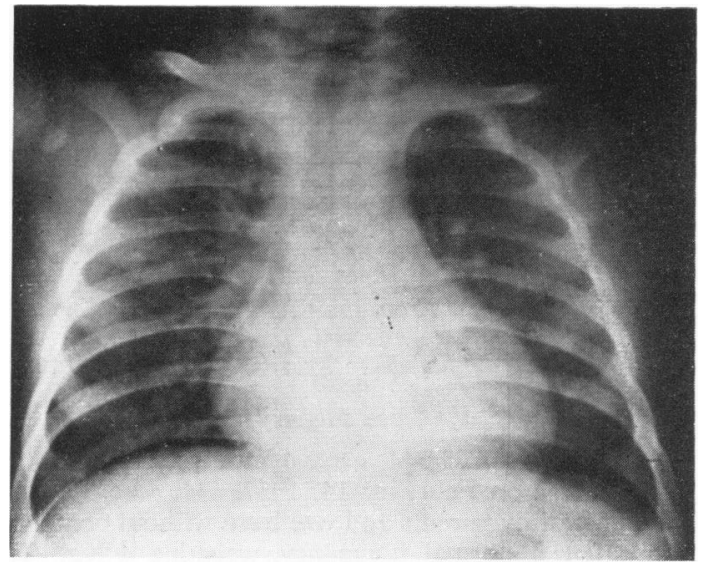

FIG. 3.-Radiograph showing heart within normal limits after two weeks' administration of vitamin $B_{1}$.

tremor or patchy eczema; he excreted a pale urine containing no reducing properties, and there was no dark staining on his diapers; there was no suggestion either from the history, physical examination or from radiographs of the long bones to suggest scurvy. We consider therefore that phenylpyruvic oligophrenia, tyrosyluria of premature infants, alcaptonuria and vitamin $\mathrm{C}$ deficiency, all four of them conditions sometimes associated with phenylpyruvic acid in the urine, were excluded.

As we could not relate phenylpyruvic acid excretion to any of these four disorders, we suppose, though possessing no certain proof, that pyruvic acid, present in excess in the tissues during vitamin $B_{1}$ deficiency may be conjugated with phenyl radical either in the liver or kidneys and then excreted in the urine. It is well known that phenols are detoxified in the liver by conjugation with sulphuric acid or organic acids. Moreover, Closs and Fölling (1936) have demonstrated the presence of phenylpyruvic acid in the urine of rats suffering from artificially produced hypothiaminosis.

\section{Summary}

A 4-month-old infant fed on a butter-flour mixture, prepared from overmilled wheat meal, developed frank beriberi with cardiac enlargement and circulatory failure, a grunting cry and loss of the patellar reflexes. All these symptoms disappeared after giving him large doses of vitamin $\mathbf{B}_{\mathbf{1}}$.

This appears to be the first case of true infantile beriberi reported in Europe.

\section{REFERENCE}

Closs, E. and Fölling, A. (1936). Z. phys. Chem., 254, 258. 